\title{
Management of Colonic Diverticulitis Tailored to Location and Severity: Comparison of the Right and the Left Colon
}

\author{
Byeoung Hoon Chung, Gi Won Ha, Min Ro Lee, Jong Hun Kim \\ Research Institute of Clinical Medicine, Chonbuk National University Medical School, Jeonju, Korea
}

\begin{abstract}
Purpose: This study assessed optimal management of colonic diverticulitis as functions of disease location and severity and factors associated with complicated diverticulitis.

Methods: This retrospective review analyzed 202 patients diagnosed between 2007 and 2014 at Chonbuk National University Hospital, South Korea, with colonic diverticulitis by using abdominopelvic computed tomography. Diverticulitis location was determined, and disease severity was categorized using the modified Hinchey classification.

Results: Patients included 108 males (53.5\%) and 94 females (46.5\%); of these, 167 patients (82.7\%) were diagnosed with right-sided and 35 (17.3\%) with left-sided colonic diverticulitis. Of the 167 patients with right-sided colonic diverticulitis, $12(7.2 \%)$ had complicated and 155 (92.8\%) had uncomplicated diverticulitis; of these, 157 patients (94.0\%) were successfully managed conservatively. Of the 35 patients with left-sided colonic diverticulitis, 23 (65.7\%) had complicated and 12 (34.3\%) had uncomplicated diverticulitis; of these, 23 patients (65.7\%) were managed surgically. Among patients with right-sided diverticulitis, those with complicated disease were significantly older $(54.3 \pm 12.7$ years vs. $42.5 \pm 13.4$ years, $\mathrm{P}$ $=0.004)$ and more likely to be smokers $(66.7 \%$ vs. $32.9 \%, \mathrm{P}=0.027)$ than those with uncomplicated disease. However, among patients with left-sided diverticulitis, those with complicated disease had significantly lower body mass index (BMI; $21.9 \pm 4.7 \mathrm{~kg} / \mathrm{m}^{2}$ vs. $25.8 \pm 4.3 \mathrm{~kg} / \mathrm{m}^{2}, \mathrm{P}=0.021$ ) than those with uncomplicated disease.

Conclusion: Conservative management may be effective in patients with right-sided diverticulitis and patients with uncomplicated left-sided colonic diverticulitis. Surgical management may be required for patients with complicated leftsided diverticulitis. Factors associated with complicated diverticulitis include older age, smoking and lower BMI.
\end{abstract}

Keywords: Colonic diverticulitis; Computed tomography; Anti-bacterial agents/therapeutic use; Treatment outcome; Risk factors

\section{INTRODUCTION}

The incidence of colonic diverticulitis is increasing, both in Asian and Western countries. This increase may be due to improvements in diagnostic tools, such as abdominopelvic computed tomography $(\mathrm{CT})$, which can provide detailed diagnosis of diverticulitis between different variants of disease progression $[1,2]$. Di-

Received: September 10, 2016 - Accepted: October 24, 2016

Correspondence to: Min Ro Lee, M.D.

Research Institute of Clinical Medicine, Chonbuk National University Medical School, 567 Baekje-daero, Deokjin-gu, Jeonju 54896, Korea Tel: +82-63-250-1570, Fax: +82-63-271-6197, E-mail: gsminro@jbnu.ac.kr

(C) 2016 The Korean Society of Coloproctology

This is an open-access article distributed under the terms of the Creative Commons Attribution NonCommercial License (http://creativecommons.org/licenses/by-nc/4.0) which permits unrestricted noncommercial use, distribution, and reproduction in any medium, provided the original work is properly cited. verticulitis can be classified as uncomplicated or complicated using a CT evaluation. Uncomplicated diverticulitis is characterized by evidence of colonic wall thickening or pericolic inflammatory changes whereas complicated diverticular disease is characterized by the presence of abscesses, fistulas, obstructions, and/or localized or free perforations. The severity of acute diverticulitis is often graded by using the modified Hinchey classification [1-4]. Surgical management of diverticulitis has been questioned, with conservative management increasingly being used in patients with diverticulitis in both the right and the left colon. Moreover, surgery may not always be appropriate in patients with a complicated form of diverticulitis.

Few studies to date have compared the managements of patients with diverticulitis in the right and the left colon. This study evaluated the management of diverticulitis as a function of disease location (right or left colon) and disease severity (complicated or 
uncomplicated). In addition, factors associated with complicated diverticulitis were determined.

\section{METHODS}

Patients diagnosed with colonic diverticulitis by using abdominopelvic CT at Chonbuk National University Hospital, South Korea, from 2007 to 2014 were retrospectively evaluated. Demographics and clinical features, including age, sex, results of physical examinations, body mass index (BMI), comorbidities, changes in bowel habits, length of hospital stay, duration of antibiotic use and bowel rest, CT findings, type of surgery, and disease recurrence, were obtained from patients' records. Abdominopelvic CT findings were categorized by using the modified Hinchey classification, with patients classified as having stages Ib, II, III, and IV diverticulitis, as well as fistula or obstruction, being defined as having complicated diverticulitis [2]. Patients without CT scan evidence of diverticulitis were excluded from the study. Categorical variables were compared by using the chi-square and Fisher exact tests whereas continuous variables were compared by using Student t-tests. A logistic regression analysis was used for the multivariate analysis. Results with $\mathrm{P}$-values $<0.05$ were considered statistically significant.

\section{RESULTS}

During the study period, 202 patients, 108 males (53.5\%) and 94 females (46.5\%), were diagnosed with diverticulitis, including 167 patients $(82.7 \%)$ with right-sided and 35 (17.3\%) with left-sided colonic diverticulitis. Patients with right-sided diverticulitis were significantly more likely to be younger $(43.4 \pm 13.7$ years vs. 65.8 \pm 15.4 years, $\mathrm{P}=0.001)$ and to be male $(58.1 \%$ vs. $31.4 \%, \mathrm{P}=$ $0.004)$, but significantly less likely to have comorbidities $(31.7 \%$ vs. $62.9 \%, P=0.013)$, than patients with left-sided diverticulitis.

Table 1. Characteristics of the patients

\begin{tabular}{|c|c|c|c|c|}
\hline Characteristic & Total $(n=202)$ & Right colon $(n=167)$ & Left colon $(n=35)$ & P-value \\
\hline$\overline{\text { Age }(\mathrm{yr})}$ & $47.2 \pm 16.3$ & $43.4 \pm 13.7$ & $65.8 \pm 15.4$ & 0.001 \\
\hline Sex, male : female & $108: 94(53.5: 46.5)$ & $97: 70$ (58.1 : 41.9) & $11: 24(31.4: 68.6)$ & 0.004 \\
\hline Body mass index $\left(\mathrm{kg} / \mathrm{m}^{2}\right)$ & $23.0 \pm 3.2$ & $23.0 \pm 3.2$ & $37.5 \pm 4.9$ & 0.732 \\
\hline Smoking & $66(32.7)$ & $59(35.3)$ & $7(20.0)$ & 0.079 \\
\hline Alcohol & $84(41.6)$ & $76(45.5)$ & $8(22.9)$ & 0.013 \\
\hline Comorbidity & $75(37.1)$ & $53(31.7)$ & $22(62.9)$ & 0.001 \\
\hline Constipation & $6(3.0)$ & $4(2.4)$ & $2(5.7)$ & 0.278 \\
\hline Recent BHC & $34(16.8)$ & $26(15.6)$ & $8(22.9)$ & 0.295 \\
\hline Body temperature $\left({ }^{\circ} \mathrm{C}\right)$ & $36.7 \pm 0.6$ & $36.7 \pm 0.5$ & $36.6 \pm 0.7$ & 0.589 \\
\hline WBC count $\left(/ \mathrm{mm}^{3}\right)$ & $12.0 \pm 7.9$ & $12.0 \pm 8.0$ & $11.7 \pm 7.8$ & 0.916 \\
\hline Tenderness & $194(96.0)$ & $162(97.0)$ & $32(91.4)$ & 0.144 \\
\hline Rebound tenderness & 113 (55.9) & $93(55.7)$ & $20(57.1)$ & 0.875 \\
\hline Multiple diverticula & $134(66.3)$ & $108(64.7)$ & $26(74.3)$ & 0.274 \\
\hline mHinchey classification & & & & 0.001 \\
\hline la & $167(82.7)$ & $155(92.8)$ & $12(34.3)$ & \\
\hline $\mathrm{lb}$ & $16(7.9)$ & $9(5.4)$ & $6(17.1)$ & \\
\hline$\|$ & $3(1.5)$ & $1(0.6)$ & $2(5.7)$ & \\
\hline III & $5(2.5)$ & $1(0.6)$ & $4(11.4)$ & \\
\hline IV & $11(5.4)$ & $1(0.6)$ & $11(31.4)$ & \\
\hline Fistula & $0(0)$ & $0(0)$ & $0(0)$ & \\
\hline Obstruction & $0(0)$ & $0(0)$ & $0(0)$ & \\
\hline Abdominal PCD & $5(2.5)$ & $3(1.8)$ & $2(5.7)$ & 0.208 \\
\hline Surgery & $33(16.3)$ & $10(6.0)$ & $23(65.7)$ & 0.001 \\
\hline NPO time (day) & $33.8 \pm 3.7$ & $3.8 \pm 3.8$ & $4.2 \pm 2.9$ & 0.490 \\
\hline Antibiotic duration (day) & $6.4 \pm 5.0$ & $5.8 \pm 4.1$ & $9.1 \pm 7.7$ & 0.020 \\
\hline Hospital days & $8.6 \pm 7.1$ & $7.6 \pm 4.5$ & $13.7 \pm 13.0$ & 0.008 \\
\hline Recurrence & $20(9.9)$ & $16(9.6)$ & $4(11.4)$ & 0.757 \\
\hline
\end{tabular}

Values are presented as mean \pm standard deviation or number (\%).

Constipation, chronic constipation; BHC, bowel habit change; WBC, white blood cell; mHinchey classification, modified Hinchey classification; PCD, percutaneous drainage; NPO, nothing per oral.

Body mass index, body temperature, WBC count were checked on admission. 
Table 2. Factors associated with the location of diverticulitis (multivariate analysis)

\begin{tabular}{lccccc}
\hline Variable & Right colon $(\mathrm{n}=167)$ & Left colon $(\mathrm{n}=35)$ & Multivariate OR & $95 \% \mathrm{Cl}$ & P-value \\
\hline Age $(\mathrm{yr})$ & $43.4 \pm 13.7$ & $65.8 \pm 15.4$ & 1.104 & $1.069-1.142$ & 0.000 \\
Female sex & $70(41.9)$ & $24(68.6)$ & 2.730 & $1.089-6.841$ & 0.032 \\
Alcohol & $76(45.5)$ & $8(22.9)$ & 0.903 & $0.270-3.018$ & 0.869 \\
Comorbidity & $53(31.7)$ & $22(62.9)$ & 0.797 & $0.282-2.254$ & 0.669 \\
\hline
\end{tabular}

Values are presented as mean \pm standard deviation or number (\%). Logistic regression analyses were used. $\mathrm{OR}$, odds ratio; $\mathrm{Cl}$, confidence interval.

Table 3. Factors associated with complicated diverticulitis in the right colon

\begin{tabular}{lccc}
\hline Variable & With complications $(\mathrm{n}=12)$ & Without complications $(\mathrm{n}=155)$ & P-value \\
\hline Age $(\mathrm{yr})$ & $54.3 \pm 12.7$ & $42.5 \pm 13.4$ & 0.004 \\
Sex, male : female & $8: 4(66.7: 33.3)$ & $89: 66(57.4: 42.6)$ & 0.532 \\
Body mass index $\left(\mathrm{kg} / \mathrm{m}^{2}\right)$ & $22.2 \pm 2.3$ & $23.0 \pm 3.2$ & 0.384 \\
Smoking & $8(66.7)$ & $51(32.9)$ & 0.027 \\
Alcohol & $8(66.7)$ & $68(43.9)$ & 0.127 \\
Comorbidity & $4(33.3)$ & $49(31.6)$ & 0.999 \\
Constipation & $0(0)$ & $4(2.6)$ & 0.999 \\
Recent BHC & $2(16.7)$ & $24(15.5)$ & 0.999 \\
Body temperature $\left({ }^{\circ} \mathrm{C}\right)$ & $36.5 \pm 0.3$ & $36.7 \pm 0.5$ & 0.111 \\
WBC count $\left./ / \mathrm{mm}^{3}\right)$ & $11.8 \pm 3.6$ & $12.0 \pm 8.2$ & 0.920 \\
Tenderness & $12(100)$ & $150(96.8)$ & 0.999 \\
Rebound tenderness & $4(33.3)$ & $89(57.4)$ & 0.106 \\
Multiple diverticula & $11(91.7)$ & $97(62.6)$ & 0.058 \\
\hline
\end{tabular}

Values are presented as mean \pm standard deviation or number (\%). Student t-test, chi-square test and Fisher exact test were used.

$\mathrm{BHC}$, bowel habit change; WBC, white blood cell.

Other variables in these 2 groups are shown in Table 1, and the results of the multivariate analysis of factors significantly associated with the location of diverticulitis are shown in Table 2.

Statistical analysis showed that factors significantly associated with complicated diverticulitis were dependent on disease location. Compared with patients with uncomplicated right-sided diverticulitis, those with complicated right-sided diverticulitis were significantly more likely to be older $(54.3 \pm 12.7$ years vs. $42.5 \pm$ 13.4 years, $\mathrm{P}=0.004)$ and to be smokers $(66.7 \%$ vs. $32.9 \%, \mathrm{P}=$ 0.027 ) (Table 3). However, among patients with left-sided diverticulitis, those with complicated disease had significantly lower BMI $\left(21.9 \pm 4.7 \mathrm{~kg} / \mathrm{m}^{2}\right.$ vs. $\left.25.8 \pm 4.3 \mathrm{~kg} / \mathrm{m}^{2}, \mathrm{P}=0.021\right)$ than those with uncomplicated disease (Table 4).

Of the 172 patients with right-sided disease, 12 (7.2\%) had complicated and 155 (92.8\%) had uncomplicated diverticulitis. Of the 12 patients with complicated diverticulitis, 7 were managed surgically, and 5 were managed conservatively. Of the 155 patients with uncomplicated diverticulitis, 152 were successfully managed conservatively. The other 3 patients were initially managed conservatively, but eventually underwent surgery (Fig. 1A).
Of the 35 patients with left-sided disease, 23 (65.7\%) had complicated and $12(34.3 \%)$ had uncomplicated diverticulitis. Of the 23 patients with complicated diverticulitis, 17 were managed surgically, and 6 were initially managed conservatively. Three of the latter 6 patients, however, failed conservative management and eventually underwent surgery. Of the 12 patients with uncomplicated diverticulitis, 9 were successfully managed conservatively, with the remaining 3 patients requiring surgery (Fig. 1B).

\section{DISCUSSION}

This retrospective analysis suggests that management of patients with colonic diverticulitis is dependent on both disease location and severity. This analysis also identified clinicopathological factors associated with both disease location and disease severity.

The demographic and the clinical characteristics of the patients in the present study were similar to those in previous studies of diverticulitis. Right-sided colonic diverticulitis has been reported to occur predominantly in relatively young males whereas leftsided diverticular disease is more common in women, with its in- 
Table 4. Factors associated with complicated diverticulitis in the left colon

\begin{tabular}{lccc}
\hline Variable & With complications $(\mathrm{n}=23)$ & Without complications $(\mathrm{n}=12)$ & P-value \\
\hline Age $(\mathrm{yr})$ & $68.2 \pm 12.5$ & $61.2 \pm 19.6$ & 0.276 \\
Sex, male : female & $9: 14(39.1: 60.9)$ & $2: 10(16.7: 83.3)$ & 0.259 \\
Body mass index $\left(\mathrm{kg} / \mathrm{m}^{2}\right)$ & $21.9 \pm 4.7$ & $25.8 \pm 4.3$ & 0.021 \\
Smoking & $5(21.7)$ & $2(16.7)$ & 0.999 \\
Alcohol & $5(21.7)$ & $3(25.0)$ & 0.999 \\
Comorbidity & $14(60.9)$ & $8(66.7)$ & 0.999 \\
Constipation & $1(4.3)$ & $1(8.3)$ & 0.999 \\
Recent BHC & $5(21.7)$ & $3(25.0)$ & 0.999 \\
Body temperature $\left({ }^{\circ} \mathrm{C}\right)$ & $36.7 \pm 0.7$ & $36.6 \pm 0.6$ & 0.852 \\
WBC count $\left./(\mathrm{mm})^{3}\right)$ & $12.7 \pm 9.1$ & $10.3 \pm 4.2$ & 0.386 \\
Tenderness & $21(91.3)$ & $11(91.7)$ & 0.999 \\
Rebound tenderness & $14(60.9)$ & $6(50.0)$ & 0.537 \\
Multiple diverticula & $19(82.6)$ & $7(58.3)$ & 0.220 \\
\hline
\end{tabular}

Values are presented as mean \pm standard deviation or number (\%). Student t-test, chi-square test and Fisher exact test were used.

BHC, bowel habit change; WBC, white blood cell.
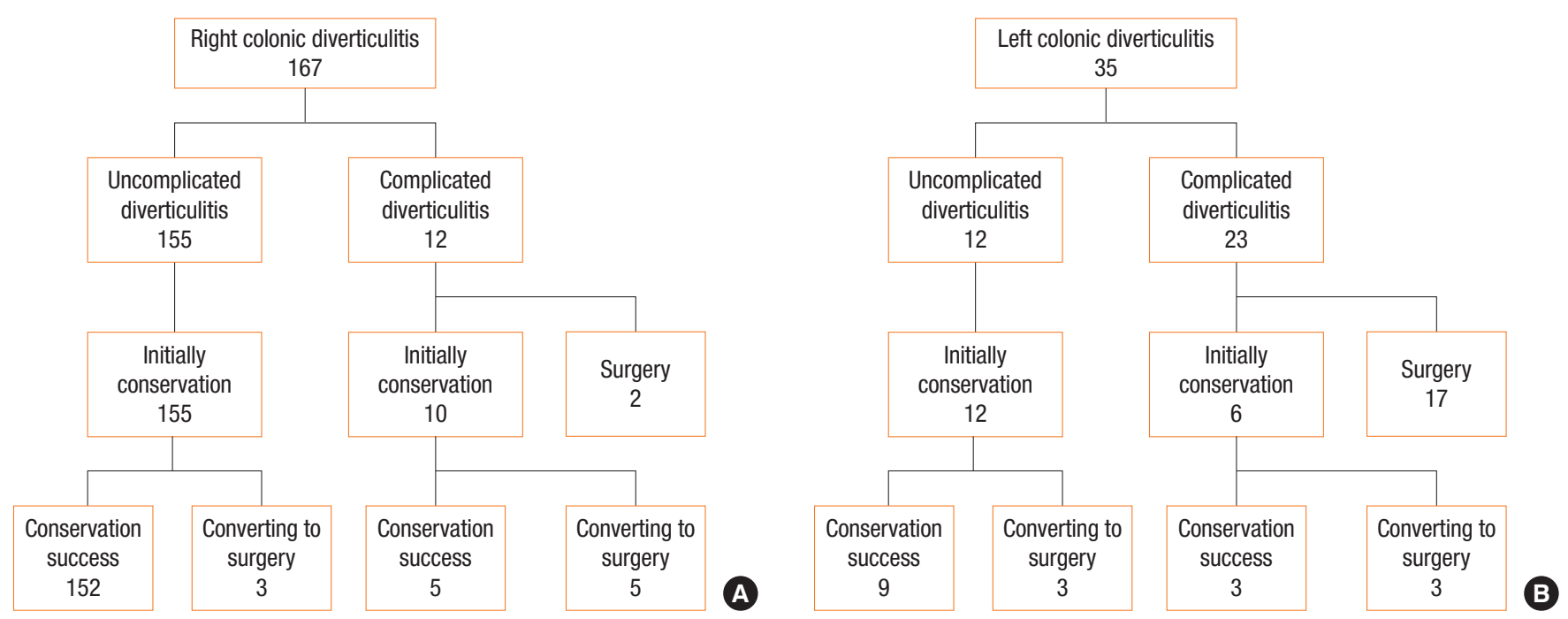

Fig. 1. Overview of patient outcomes in patients with right colonic diverticulitis (A) and in patients with left colonic diverticulitis (B).

cidence increasing with age [5-9]. The present study also found that left-sided colonic diverticulitis was significantly associated with both older age and female sex.

Diverticulitis in younger patients $(<50$ years) has been described as more virulent and more likely to be associated with complications $[10,11]$. In addition, smoking was found to be a risk factor in patients with symptomatic disease and to be related to complications $[12,13]$. The present study found that older age and smoking were significantly associated with complicated rightsided diverticulitis whereas low BMI was significantly associated with complicated left-sided diverticulitis. To our knowledge, no previous study has assessed factors associated with locations of complicated diverticulitis from the same population. The findings of this study suggest that special considerations may be required to manage patients with factors associated with complicated diverticulitis. These patients initially have uncomplicated diverticulitis, which becomes aggravated and complicated, resulting in a switch from conservative to surgical management. Additional large scale studies are required to confirm these findings, especially in patients with complicated left-sided diverticulitis.

Conservative management has been shown to be effective in patients with uncomplicated diverticulitis, both in the right and the left colon [14-19]. However, the optimal treatment of complicated diverticulitis has not been determined as improvements in surgi- 
cal techniques and medical management have led to changes in management. Traditionally, most patients with complicated diverticulitis have been managed surgically, by, for example, resection of the perforated segment of the colon [20-23]. Conservative management of complicated diverticulitis has been reported to be successful $[24,25]$. Medical management in patients with complicated diverticulitis may have the goal of converting an emergency surgery to an elective one $[2,26,27]$.

The results of the present study suggest that conservative management may be effective in patients with right-sided colonic diverticulitis. Of the 155 patients with uncomplicated right-sided diverticulitis, 152 (98\%) were treated conservatively, and only 12 of the 167 patients (7\%) with right-sided diverticulitis had complicated disease. Of those 12 patients, only 2 required emergency surgery for acute peritonitis and sepsis. Three patients with uncomplicated and 5 with complicated right-sided diverticulitis were initially managed conservatively, but eventually underwent a right hemicolectomy. A review of the medical records and the radiologic findings could not identify any criteria or indications for surgery in these patients, suggesting that these patients may have undergone unnecessary surgery that had been performed at the discretion of a surgeon not specializing in colorectal surgery. Those patients likely could have been managed conservatively.

Because the number of patients with left-sided colonic diverticulitis was relatively small, we could not determine any effective treatment modality. Our findings suggest, however, that conservative management may be effective for patients with uncomplicated diverticulitis, but that surgical management may be better for patients with complicated diverticulitis. Of the 23 patients with complicated left-sided diverticulitis, 20 (87\%) underwent surgery, with 15 having Hinchey stage III or IV disease requiring emergency surgery.

This study had several limitations, including its retrospective design and its performance at a single tertiary center where almost all patients were Asian. Moreover, only inpatients were included; no outpatients had mild diverticulitis. Therefore, this study was limited in assessing the clinical features of all patients diagnosed with diverticulitis. In addition, the number of patients with left-sided diverticulitis was much smaller than the number with right colonic-sided diverticulitis. Finally, this study did not evaluate the long-term effects of conservative management of diverticulitis, specifically the recurrence rate.

In conclusion, conservative management may be effective in patients with right-sided colonic diverticulitis, whether complicated or uncomplicated, and in patients with uncomplicated left-sided diverticulitis. Patients with complicated left-sided diverticulitis may, however, require surgical management. In addition, special attention should be paid in managing patients with factors associated with complications, such as older age and smoking in patients with right-sided and low BMI in patients with left-sided complicated diverticulitis.

\section{CONFLICT OF INTEREST}

No potential conflict of interest relevant to this article was reported.

\section{REFERENCES}

1. Ambrosetti P, Jenny A, Becker C, Terrier TF, Morel P. Acute left colonic diverticulitis: compared performance of computed tomography and water-soluble contrast enema: prospective evaluation of 420 patients. Dis Colon Rectum 2000;43:1363-7.

2. Kaiser AM, Jiang JK, Lake JP, Ault G, Artinyan A, Gonzalez-Ruiz C, et al. The management of complicated diverticulitis and the role of computed tomography. Am J Gastroenterol 2005;100:910-7.

3. Hachigian MP, Honickman S, Eisenstat TE, Rubin RJ, Salvati EP. Computed tomography in the initial management of acute leftsided diverticulitis. Dis Colon Rectum 1992;35:1123-9.

4. Rao PM, Rhea JT, Novelline RA, Dobbins JM, Lawrason JN, Sacknoff R, et al. Helical CT with only colonic contrast material for diagnosing diverticulitis: prospective evaluation of 150 patients. AJR Am J Roentgenol 1998;170:1445-9.

5. Lo CY, Chu KW. Acute diverticulitis of the right colon. Am J Surg 1996;171:244-6.

6. Lee IK, Jung SE, Gorden DL, Lee YS, Jung DY, Oh ST, et al. The diagnostic criteria for right colonic diverticulitis: prospective evaluation of 100 patients. Int J Colorectal Dis 2008;23:1151-7.

7. Lee IK, Lee YS, Kim SJ, Gorden DL, Won DY, Kim HJ, et al. Laparoscopic and open surgery for right colonic diverticulitis. Am Surg 2010;76:486-91.

8. Parks TG. Natural history of diverticular disease of the colon. Clin Gastroenterol 1975;4:53-69.

9. Commane DM, Arasaradnam RP, Mills S, Mathers JC, Bradburn M. Diet, ageing and genetic factors in the pathogenesis of diverticular disease. World J Gastroenterol 2009;15:2479-88.

10. Cortesini C, Pantalone D. Usefulness of colonic motility study in identifying patients at risk for complicated diverticular disease. Dis Colon Rectum 1991;34:339-42.

11. Cranston D, McWhinnie D, Collin J. Dietary fibre and gastrointestinal disease. Br J Surg 1988;75:508-12.

12. Aldoori WH, Giovannucci EL, Rimm EB, Ascherio A, Stampfer MJ, Colditz GA, et al. Prospective study of physical activity and the risk of symptomatic diverticular disease in men. Gut 1995;36: 276-82.

13. Papagrigoriadis S, Macey L, Bourantas N, Rennie JA. Smoking may be associated with complications in diverticular disease. $\mathrm{Br} J$ Surg 1999;86:923-6.

14. Alonso S, Pera M, Parés D, Pascual M, Gil MJ, Courtier R, et al. Outpatient treatment of patients with uncomplicated acute diverticulitis. Colorectal Dis 2010;12(10 Online):e278-82.

15. Etzioni DA, Chiu VY, Cannom RR, Burchette RJ, Haigh PI, Abbas MA. Outpatient treatment of acute diverticulitis: rates and predictors of failure. Dis Colon Rectum 2010;53:861-5. 
16. Feingold D, Steele SR, Lee S, Kaiser A, Boushey R, Buie WD, et al. Practice parameters for the treatment of sigmoid diverticulitis. Dis Colon Rectum 2014;57:284-94.

17. Park HC, Chang MY, Lee BH. Nonoperative management of right colonic diverticulitis using radiologic evaluation. Colorectal Dis 2010;12:105-8.

18. Tan KK, Wong J, Sim R. Non-operative treatment of right-sided colonic diverticulitis has good long-term outcome: a review of 226 patients. Int J Colorectal Dis 2013;28:849-54.

19. Ha GW, Lee MR, Kim JH. Efficacy of conservative management in patients with right colonic diverticulitis. ANZ J Surg 2015 Mar 19 [Epub]. http://doi.org/10.1111/ans.13028.

20. Blair NP, Germann E. Surgical management of acute sigmoid diverticulitis. Am J Surg 2002;183:525-8.

21. Mastrorilli M, Mastrorilli G, Martini A, Santo C, Maresca M. Surgical management of acute sigmoid diverticulitis. Ann Ital Chir 2008;79:311-20.

22. Fang JF, Chen RJ, Lin BC, Hsu YB, Kao JL, Chen MF. Aggressive resection is indicated for cecal diverticulitis. Am J Surg 2003;185: 135-40.

23. Lane JS, Sarkar R, Schmit PJ, Chandler CF, Thompson JE Jr. Surgical approach to cecal diverticulitis. J Am Coll Surg 1999;188: 629-34.

24. Dharmarajan S, Hunt SR, Birnbaum EH, Fleshman JW, Mutch MG. The efficacy of nonoperative management of acute complicated diverticulitis. Dis Colon Rectum 2011;54:663-71.

25. Nelson RS, Ewing BM, Wengert TJ, Thorson AG. Clinical outcomes of complicated diverticulitis managed nonoperatively. Am J Surg 2008;196:969-72.

26. Ambrosetti P, Becker C, Terrier F. Colonic diverticulitis: impact of imaging on surgical management -- a prospective study of 542 patients. Eur Radiol 2002;12:1145-9.

27. Klarenbeek BR, Samuels M, van der Wal MA, van der Peet DL, Meijerink WJ, Cuesta MA. Indications for elective sigmoid resection in diverticular disease. Ann Surg 2010;251:670-4. 